THE ENVIRONMENT IN ASIA PACIFIC HARBOURS 


\section{The Environment in Asia Pacific Harbours}

Edited by

Eric Wolanski, PhD, DSc, FTSE, FIE Aust Australian Institute of Marine Science,

Townsville, Australia

算 Springer 
A C.I.P. Catalogue record for this book is available from the Library of Congress.

ISBN-10 1-4020-3654-X (HB)

ISBN-13 978-1-4020-3654-5 (HB)

ISBN-10 1-4020-3655-8 (e-book)

ISBN-13 978-1-4020-3655-2 (e-book)

Published by Springer,

P.O. Box 17, 3300 AA Dordrecht, The Netherlands.

www.springer.com

Printed on acid-free paper

All Rights Reserved

(C) 2006 Springer

No part of this work may be reproduced, stored in a retrieval system, or transmitted

in any form or by any means, electronic, mechanical, photocopying, microfilming, recording

or otherwise, without written permission from the Publisher, with the exception

of any material supplied specifically for the purpose of being entered

and executed on a computer system, for exclusive use by the purchaser of the work.

Printed in the Netherlands. 


\section{ABOUT THE EDITOR}

Dr. Eric Wolanski, PhD, DSc, FTSE, FIE Aust, is a coastal oceanographer and a leading scientist at the Australian Institute of Marine Science. He obtained a B.Sc. degree in civil engineering from the Catholic University of Louvain, a M.Sc. degree in civil and geological engineering from Princeton University, and a $\mathrm{PhD}$ in environmental engineering from The Johns Hopkins University.

His research interests range from the oceanography of coral reefs, mangroves, and muddy estuaries, to the interaction between physical and biological processes determining ecosystem health in tropical waters. He has more than 280 publications.

$\mathrm{He}$ is a fellow of the Australian Academy of Technological Sciences and Engineering, the Institution of Engineers Australia, and l'Académie Royale des Sciences d'Outre-Mer. He was awarded an Australian Centenary medal for services in estuarine and coastal oceanography, a Doctorate Honoris Causa from the Catholic University of Louvain, a Queensland Information Technology and Telecommunication award for excellence, and he is an Erasmus Mundus scholar.

$\mathrm{He}$ is the chief editor of Estuarine, Coastal and Shelf Science and Wetlands Ecology and Management. He is a member of the editorial board of Journal of Coastal Research, Journal of Marine Systems, and Continental Shelf Research. He is a member of the Scientific \& Policy Committee of the Japan-based International Center for Environmental Management of Enclosed Coastal Seas. 


\section{FOREWORD}

In the USA, Asia and Europe, as well as worldwide, trade is growing rapidly and much of it depends on shipping. This is leading to the development of mega-cities and mega-harbours. The marine environment is degrading. Is increasing trade ecologically sustainable? This book addresses this question through harbours in the Asia Pacific region, including Tokyo Bay, the Pearl Estuary, Hong Kong, Shanghai, Ho Chi Minh City, Manila Bay, Jakarta Bay, Bangkok, Singapore, Klang, Pearl Harbour, and Darwin. Much of the world trade goes through these harbours. This book demonstrates, through the writing of eminent scientists in each of these countries, the oceanography and ecosystem science necessary to understand how these urbanised marine ecosystems function. It offers science-based solutions to achieve ecologically sustainable development. These lessons are important not only for the Asia Pacific Region, including Australia, but also worldwide.

The book is a wake-up call that all the countries in the Asia Pacific are facing the same, serious socio-economic and environmental problems with varying scales. Each of these countries addresses these issues differently. This book shows that we have much to learn from each other to ensure that development does not need to be at the cost of the environment. I commend this book for its comprehensive coverage of the links between oceanography, ecosystem processes, and socio-economic issues. I hope it will create constructive discussion and awareness of the potential pitfalls and possibilities for the Asia Pacific region and the need for integration our efforts to deal with these issues.

This book by Eric Wolanski, a leading scientist at the Australian Institute of Marine Science should be taken seriously by all governments throughout the region.

The Right Honourable Malcolm Fraser, A.C., C.H.

Former Prime Minister of Australia 


\section{PREFACE}

We live in a world that is increasingly dependent on international trade and transport. Measured both by volume and by value, most imports and exports travel by sea. Ports and harbours are the essential gateways through which all this marine traffic must pass. Expansion is leading to the development of mega-cities and megaharbours. Inevitably, these are under further pressures to expand, and to work more efficiently. At the same time there is increased awareness of the need for maintaining healthy marine environments in and around these busy coastal areas. In many cases, these marine environments are degrading. Coastal managers and politicians are asking whether, and if so how, increasing trade can be balanced with ecologically sustainable environments.

This book addresses this challenge by presenting a series of studies of harbours in the Asia Pacific region, including Tokyo Bay, the Pearl Estuary, Hong Kong, Shanghai, Ho Chi Minh City, Manila Bay, Jakarta Bay, Bangkok, Singapore, Klang, Pearl Harbour, and Darwin. Much of the world trade goes through these harbours. Each individual harbour has its own special circumstances. Nevertheless, internationally there is much to be learned by exchange of information on existing management practices in different ports, and within different coastal areas.

These detailed examples demonstrate, through the writing and insights of eminent scientists in several countries, the oceanography and ecosystem science necessary to understand how these urbanised marine ecosystems function. The book offers science-based solutions to achieve ecologically sustainable development. These lessons are fundamentally important for the Asia Pacific Region, but they will also substantially inform similar analyses of port and harbour management and practices worldwide.

\section{David Pugh}

Chairman, Intergovernmental Oceanographic Commission of UNESCO.

Dept. of Earth and Ocean Sciences

University of Liverpool

4 Brownlow Street

Liverpool L69 3GP, UK 


\section{CONTENTS}

Contributors $\quad \mathrm{XV}$

1. Increasing trade and urbanisation of the Asia Pacific coast Eric Wolanski

2. Tokyo Bay: its environmental status - past, present and future Keita Furukawa and Tomonari Okada

3. Ecological network linked by the planktonic larvae of the clam Rudipates Philippinarum in Tokyo Bay Hirofumi Hinata and Keita Furukawa

4. Circulation processes in Tokyo Bay

Keisuke Nakayama

5. Effects of oceanic water intrusion on the Tokyo Bay environment Hirofumi Hinata

6. Influence of the deep waterway project on the Changjiang Estuary Jianrong ZHU, Pingxing DING, Liquan ZHANG, Hui WU, and Huijiang $C A O$

7. Impact of human activities on the health of ecosystems in the Changjiang Delta region.

Jing ZHANG, Shi Lun YANG, Zhao Li XU, and Ying $W U$

8. Geographical and economical setting of the Pearl River estuary Mingjiang ZHOU, Chaoyu WU, Shiyu LI, Xiaohong WANG, and Qiuhai LIU

9. Physical processes and sediment dynamics in the Pearl River Lixian DONG, Jilan SU, Yan LI, Xiaoming XIA, and Weibing GUAN

10. Water quality and phytoplankton blooms in the Pearl River estuary Yan LI, Liangmin HUANG, Jianfang CHEN, Mingjiang ZHOU, and Yehui TAN 
11. Pollution studies on mangroves in Hong Kong and mainland China Nora F.Y. Tam

12. Field and model studies of water quality in Hong Kong Kwok-Leung Pun

13. Eutrophication dynamics in Hong Kong coastal waters: physical and biological interactions

Joseph H.W. LEE, Paul J. Harrison, Cuiping KUANG, and Kedong YIN

14. Marine communities and introduced species in Pearl Harbor, O'ahu, Hawai' $\mathrm{i}$

Steve L. Coles

15. Physical environment in the Gulf of Thailand with emphasis on three important ports

Suphat Vongvisessomjai

16. Environmental issues in the Gulf of Thailand

Gullaya Wattayakorn

17. The environment in Ho Chi Minh City harbours

Nguyen Huu Nhan

18. Biophysical environment of Manila Bay - then and now

Gil S. Jacinto, Imelda B. Velasquez,

Maria Lourdes San Diego-McGlone,

Cesar L. Villanoy, and Fernando B. Siringan

19. Manila Bay: environmental challenges and opportunities

G.S. Jacinto, R.V. Azanza, I.B. Velasquez, and F.P. Siringan

20. Carbon flux through bacteria in a eutrophic tropical environment:

Port Klang waters

Choon-Weng Lee and Chui-Wei Bong

21. Phytoplankton structure in the tropical port waters of Singapore Karina Yew-Hoong GIN, Michael J. Holmes,

Sheng ZHANG, and Xiaohua LIN

22. Marine habitats in one of the world's busiest harbours 
23. The physical oceanography of Singapore coastal waters and its implications for oil spills

Eng Soon CHAN, Pavel Tkalich,

Karina Yew-Hoong GIN, and Jeffrey P. Obbard

24. Managing the port of Jakarta Bay: overcoming the legacy of 400 years of adhoc development

Dietriech G. Bengen, Maurice Knight, and Ian Dutton

25. Darwin Harbour: water quality and ecosystem structure in a tropical harbour in the early stages of urban development

A. D. McKinnon, N. Smit, S. Townsend, and S. Duggan

26. Hydrodynamics of Darwin Harbour

David Williams, Eric Wolanski, and Simon Spagnol

27. An estuarine ecohydrology model of Darwin Harbour, Australia Eric Wolanski, A. David McKinnon, David Williams, and Daniel M. Alongi

28. Is harbour development ecologically sustainable?

Eric Wolanski

Index

495 


\section{CONTRIBUTORS}

Daniel M. Alongi

Australian Institute of Marine

Science

PMB No. 3

Townsville MC, Queensland 4810

Australia

E-mail: d.alongi@aims.gov.au

Rhodora V. Azanza

Marine Science Institute

University of the Philippines

Diliman, Quezon City

Philippines

E-mail: rhod@upmsi.ph

Dietriech G. Bengen

Faculty of Fisheries and Marine

Science

Bogor Agricultural University

Kampus IPB Darmaga

Bogor 16680

Indonesia

E-mail: dieter@indo.net.id

Chui-Wei Bong

Laboratory of Microbial Ecology

Institute of Biological Sciences

University of Malaya,

50603 Kuala Lumpur

Malaysia

E-mail: chuiweibong@yahoo.com
Huijiang CAO

State Key Laboratory of Estuarine and Coastal Research

East China Normal University

Shanghai 200062,

China

E-mail: tycao81@yahoo.com.cn

Eng Soon CHAN

Tropical Marine Science Institute

National University of Singapore

14 Science Drive 4

Singapore 117543

E-mail: tmsdir@nus.edu.sg

Loke Ming Chou

Department of Biological Sciences

National University of Singapore

14 Science Drive 4

Singapore 117543

E-mail: dbsclm@nus.edu.sg

Steve L. Coles

Department of Natural Sciences

Bishop Museum

Honolulu, Hawai'i

USA

E-mail: slcoles@bishopmuseum.org

Pingxing DING

State Key Laboratory of Estuarine

and Coastal Research

East China Normal University

Shanghai 200062

China

E-mail: pxding@sklec.ecnu.edu.cn 


\section{Lixian DONG}

Second Institute of Oceanography

State Oceanic Administration

P.O. Box 1207

36 Bao-Chu-Bei-Lu

Hangzhou, Zhejiang 310012

China

E-mail: Lixian_dong@yahoo.com.cn

Samantha Duggan

Australian Institute of Marine

Science

PMB No. 3

Townsville MC, Queensland 4810

Australia

E-mail: s.duggan@aims.gov.au

Ian Dutton

The Nature Conservancy

5410 Grosvenor Lane, Suite 100

Bethesda, MD 20814-2144

USA

E-mail: idutton@tnc.org

The Right Honourable Malcolm

Fraser, A.C., C.H.

Level 32, 101 Collins Street

Melbourne Victoria 3000

Australia

Fax : 61-3-96541301

Keita Furukawa

National Institute for Land and

Infrastructure Management

3-1-1, Nagase, Yokusuka 239-0826

Japan

E-mail: furukawa-

k92y2@ysk.nilim.go.jp

Karina Yew-Hoong GIN

School of Civil and Environmental

Engineering

Nanyang Technological University

Singapore

E-mail: CYHGin@ntu.edu.sg
Weibing GUAN

Second Institute of Oceanography

State Oceanic Administration

P.O. Box 1207

36 Bao-Chu-Bei-Lu

Hangzhou, Zhejiang 310012

China

E-mail:wbguan@vip.sina.com

Paul J. Harrison

Atmospheric, Marine and Coastal

Environment Program

Hong Kong University of Science and Technology,

Clear Water Bay, Kowloon

Hong Kong SAR

China

E-mail: harrison@ust.hk

Hirofumi Hinata

National Institute for Land and

Infrastructure Management

Nagase 3-1-1, Yokosuka

Japan

Email: hinata-h92y2@ysk.nilim.go.jp

Michael J. Holmes

Tropical Marine Science Institute

National University of Singapore

Singapore 117543

E-mail: tmshmj@nus.edu.sg

Liangmin HUANG

Key Laboratory of Tropical Marine

Environmental Dynamics

South China Sea Institute of

Oceanography

Chinese Academy of Science,

Guangzhou 510301

China

E-mail: hlm@scsio.ac.cn 
Gil S. Jacinto

Marine Science Institute, University of the Philippines

Diliman, Quezon City

Philippines

E-mail: gilj@upmsi.ph

Maurice Knight

8200 Jakarta Place

Dulles, VA 20189-8200

USA

E-mail:

MauriceKnight@attglobal.net

Cuiping P. KUANG

Department of Civil Engineering

The University of Hong Kong,

Pokfulam

Hong Kong SAR

China

E-mail: ckuang@hkucc.hku.hk

Choon-Weng Lee

Laboratory of Microbial Ecology

Institute of Biological Sciences

University of Malaya

50603 Kuala Lumpur

Malaysia

E-mail address: lee@um.edu.my

Joseph H.W. LEE

Department of Civil Engineering

The University of Hong Kong,

Pokfulam

Hong Kong SAR

China

E-mail: hreclhw@hkucc.hku.hk

Shiyu LI

Sun Yat-sen University

135 West Xingang Road

Guangzhou 510275

China

E-mail: eeslsy@zsu.edu.cn
Yan LI

State Key Laboratory of Marine

Environmental Science

Xiamen University

422 Simingnan Road

Ximen

Fujian 361005

China

E-mail: liyan@xmu.edu.cn

Xiaohua LIN

Tropical Marine Science Institute National University of Singapore Singapore 117543

E-mail: lin_xh@hotmail.com

Qiuhai LIU

Sun Yat-sen University

135 West Xingang Road

Guangzhou 510275

China

E-mail: eepeios1@zsu.edu.cn

A. David McKinnon

Australian Institute of Marine

Science

PMB. No. 3, Townsville M.C.

Queensland 4810

Australia

E-mail: d.mckinnon@aims.gov.au

Keisuke Nakayama

National Institute for Land and

Infrastructure Management,

Nagase 3-1-1, Yokosuka

Japan

E-mail: nakayama-

k92y2@ysk.nilim.go.jp

Nguyen Huu Nhan

Southern Region

Hydrometeorological Service

8 Mac Dinh Chi Street, Dist 1

Ho Chi Mi City

Vietnam

E-mail: huu-nhan@hcm.vnn.vn 
Jeffrey P. Obbard

Tropical Marine Science Institute

National University of Singapore

14 Science Drive 4

Singapore 117543

E-mail: chejpo@nus.edu.sg

Tomonari Okada

National Institute for Land and

Infrastructure Management,

Nagase 3-1-1, Yokosuka

Japan

E-mail: okada-t92y2@ysk.nilim.go.jp

David Pugh

Department of Earth and Ocean

Sciences

University of Liverpool

4 Brownlow Street

Liverpool L69 3GP

UK

E-mail: D.Pugh@mac.com

Kwok-Leung PUN

Chu Hai College of Higher Education

Yi Lok Street, Riviera Gardens

Tsuen Wan, New Territories

Hong Kong SAR

China

E-mail: klpun@chuhai.edu.hk

Maria Lourdes San Diego-McGlone

Marine Science Institute,

University of the Philippines

Diliman, Quezon City

Philippines.

E-mail: mcglonem@upmsi.ph

Fernando B. Siringan

National Institute of Geological

Sciences

University of the Philippines

Diliman, Quezon City

Philippines

E-mail: ando_nigs@yahoo.com
Neil Smit

Department of Infrastructure, Planning and Environment

PO Box 30

Palmerston 0831, Northern Territory

Australia

E-mail:

Neil.Smit@plmbay.pwcnt.nt.gov.au

Simon Spagnol

Australian Institute of Marine

Science

PMB No. 3

Townsville MC, Queensland 4810

Australia

E-mail: s.spagnol@aims.gov.au

Jilan SU

Second Institute of Oceanography

State Oceanic Administration

P.O. Box 1207

36 Bao-Chu-Bei-Lu

Hangzhou, Zhejiang 310012

China

E-mail: sujil@zgb.com.cn

Nora Fung-yee TAM

Department of Biology and

Chemistry,

City University of Hong Kong

Tat Chee Avenue, Kowloon

Hong Kong SAR

China

E-mail: bhntam@cityu.edu.hk

Yehui TAN

Key Laboratory of Tropical Marine

Environmental Dynamics

South China Sea Institute of

Oceanography

Chinese Academy of Science

Guangzhou 510301

China

E-mail: tanyh@scsio.ac.cn 
Pavel Tkalich

Tropical Marine Science Institute

National University of Singapore

14 Science Drive 4

Singapore 117543

E-mail: tmspt@nus.edu.sg

Simon Townsend

Department of Infrastructure,

Planning and the Environment,

PO Box 30

Palmerston 0831, Northern Territory

Australia

E-mail :Simon.Townsend@nt.gov.au

Imelda B. Velasquez

Marine Science Institute, University

of the Philippines

Diliman, Quezon City

Philippines

E-mail: dang@upmsi.ph

Cesar L. Villanoy

Marine Science Institute, University

of the Philippines

Diliman, Quezon City

Philippines

E-mail: cesarv@upmsi.ph

Suphat Vongvisessomjai

c/o Water Engineering and

Management

School of Civil Engineering

Asian Institute of Technology

P.O Box 4, Klong Luang

Pathumthani 12120

Thailand.

Xiaohong WANG

Sun Yat-sen University

135 West Xingang Road

Guangzhou 510275

China.

E-mail:

wangsxiaohong81@yahoo.com.cn
Gullaya Wattayakorn

Department of Marine Science

Chulalongkorn University

Bangkok 10330

Thailand

E-mail: gullaya.w@chula.ac.th

David Williams

Department of Infrastructure, Planning and the Environment, Natural Resources Division, PO Box 30, Palmerston 0831, Northern Territory

Australia

E-mail: david.williams@nt.gov.au

Eric Wolanski, FTSE, FIE Aust

Australian Institute of Marine

Science

PMB No. 3

Townsville MC, Queensland 4810

Australia.

E-mail: e.wolanski@aims.gov.au

Chaoyu WU

Sun Yat-sen University

135 West Xingang Road

Guangzhou 510275

China

E-mail: eeswcy@zsu.edu.cn

Hui WU

State Key Laboratory of Estuarine and Coastal Research

East China Normal University

Shanghai 200062

China

E-mail: woo_hui@hotmail.com

Ying WU

State Key Laboratory of Estuarine and Coastal Research

East China Normal University

3663 Zhongshan Road North

Shanghai 20006

P.R. China 
Xiaoming XIA

Second Institute of Oceanography

State Oceanic Administration

P.O. Box 1207

36 Bao-Chu-Bei-Lu

Hangzhou, Zhejiang 310012

China

E-mail: xiaxm@mail.hz.zj.cn

\section{Zhao Li XU}

East China Sea Fishery Research

Institute

Chinese Academy of Fishery

Sciences

334 Jungong Road

Shanghai 200090

P.R. China

Shi Lun YANG

State Key Laboratory of Estuarine and Coastal Research

East China Normal University

3663 Zhongshan Road North

Shanghai 200062

P.R. China

\section{Kedong D. YIN}

Atmospheric, Marine and Coastal

Environment Program

Hong Kong University of Science and Technology

Clear Water Bay, Kowloon, Hong

Kong SAR, China.

and

Key Laboratory of Tropical Marine

Environmental Dynamics

South China Sea Institute of

Oceanology

Chinese Academy of Sciences,

Guangzhou

China

E-mail: kyin@ust.hk
Jing ZHANG

State Key Laboratory of Estuarine and Coastal Research

East China Normal University

3663 Zhongshan Road North,

Shanghai 200062

P.R. China

and

College of Chemistry and Chemical

Engineering

Ocean University of China

5 Yushan Road, Qingdao 266003

P.R. China

E-mail: jzhang@sklec.ecnu.edu.cn

Liquan ZHANG

State Key Laboratory of Estuarine and Coastal Research

East China Normal University

Shanghai 200062, China

E-mail: lqzhang@sklec.ecnu.edu.cn

Sheng ZHANG

Tropical Marine Science Institute National University of Singapore Singapore 117543

E-mail: shengzhang@ucsd.edu

Mingjiang ZHOU

Institute of Oceanology

Chinese Academy of Sciences

7 Nanhai Road, Qingdao 266071

China.

E-mail: mjzhou@ms.qdio.ac.cn

Jianrong ZHU

State Key Laboratory of Estuarine

and Coastal Research

East China Normal University

Shanghai 200062

China

E-mail:.jrzhu@sklec.ecnu.edu.cn 